\title{
High-Birefringent Fiber Loop Mirror Sensors: New Developments
}

\author{
Marta S. Ferreira, Ricardo M. Silva and Orlando Frazão \\ INESC Porto, Porto \\ Portugal
}

\section{Introduction}

The fiber loop mirror based on a ring configuration is one of the devices in optical fibers most used in communications and sensors (Mortimore, 1988). The device is formed when the two output ports of a directional coupler are spliced. In this configuration, the two waves at the coupler outputs travel in opposite directions but following the same optical paths in an optical fiber ring, which assures constructive interference as the waves re-enter the coupler. Thus, all light is reflected to the input port containing losses essentially in the fiber, the splice region and the coupler. Due to this "mirror" characteristic, the device is frequently used in the formation of resonant cavities in optical fiber lasers (Urquhart, 1989). A structure of this kind, with interesting properties, occurs when the ring contains a section of fiber with high-birefringence. When this happens, an interference pattern is generated. It depends only on the fiber birefringence and length, being independent of the remaining ring extension (Fang \& Claus, 1995).

This chapter provides an overview of the state-of-the-art, birefringence concepts, and new developments of high-birefringence fiber loop mirror configurations that can be used as sensing elements.

\section{State-of-the-art}

In this section, a brief review about the state-of-the-art using high-birefringent fiber loop mirror (Hi-Bi FLM) configurations is described. In order to give a clear view about the evolution of Hi-Bi FLM setups, a sum up with the years of publications and the most important breakthroughs are shown in table 1.

The first Hi-Bi fiber Sagnac loop sensor for temperature measurement was proposed in 1997. The configuration, schematically shown in Figure $1 \mathrm{a}$ ), consisted of a $3 \mathrm{~dB}$ simple polarization maintaining coupler, constituted by a bow-tie fiber. By cross splicing the output ports at $\pi / 2$, they guaranteed that both port lengths were different, forming an unbalanced Sagnac loop interferometer.

The temperature sensor could operate both in transmission and reflection, and its functioning did not depend on the light polarization at the input port. When compared with other temperature optical sensors (fiber Bragg gratings), this configuration presented higher sensitivity (Delarosa et al., 1997; Starodumov et al., 1997). In the same year, a strain sensor 


\begin{tabular}{c|l}
\hline Year & \multicolumn{1}{|c}{ Breakthrough of Hi-Bi FLM configurations } \\
\hline 1997 & $\begin{array}{l}\text { Temperature sensor (Starodumov et al., 1997); temperature sensing in } \\
\text { NIR (Delarosa et al., 1997); strain sensor (Campbell et al., 1997) } \\
\text { Strain sensor (Campbell et al., 1999) } \\
2094\end{array} \quad \begin{array}{l}\text { Temperature PCF sensor (Kim, D. H. \& Kang, 2004); temperature insensitivity } \\
\text { using PCF (Zhao et al., 2004) } \\
\text { Interrogation system using PCF (Yang et al., 2005); displacement sensor (Liu et al., } \\
\text { 2005) } \\
\text { Liquid level sensor (Dong, B. et al., 2006); FBG interrogation system (Silva et al., } \\
\text { 2011); LPG/Hi-Bi FLM (Frazao et al., 2006b) } \\
\text { Review of Hi-Bi FLM sensors (Frazao et al., 2007a); strain PCF sensor (Dong, X. Y. } \\
\text { et al., 2007; Frazao et al., 2007b) ; chemical etching (Frazao et al., 2007c); } \\
\text { concatenated FLM (Frazao et al., 2007d) } \\
\text { Temperature Erbium Hi-Bi fiber (Frazao et al., 2008a); refractive index sensor } \\
\text { (Frazao et al., 2008b); multiparameter sensor using side-hole fiber (Frazao et al., } \\
\text { 2008c); pressure PCF sensor (Fu et al., 2008); FBG/Hi-Bi FLM (Zhou et al., 2008); } \\
\text { current sensor (Marques et al., 2008) } \\
\text { Multiplexing Hi-Bi FLM (Fu et al., 2009); strain and temperature discrimination } \\
\text { using two Hi-Bi fibers (Han et al., 2009); hollow-core PCF sensor (Kim, G. et al., } \\
\text { 2009); holey fiber filled with metal indium (Kim, B. H. et al., 2009) } \\
\text { Torsion PCF sensor (Kim, H. M. et al., 2010); curvature PCF sensor (Gong et al., } \\
\text { 2010); pressure-induced SMF (Jin et al., 2010); long distance remote interrogation } \\
\text { system (Lee et al., 2010); small core PCF (Andre et al., 2010); intensity strain sensor } \\
\text { (Qian et al., 2010); suspended twin-core (Frazao et al., 2010); displacement PCF } \\
\text { sensor (Zhang et al., 2010) } \\
\text { Hi-Bi FLM with an output port probe (Frazao et al., 2011); LPG/Sagnac Loop (Kang } \\
\text { et al., 2011); curvature PCF sensor (Hwang et al., 2011); Hi-Bi photonic bandgap } \\
\text { Bragg fiber (Ferreira et al., 2011); transverse mechanical load (Zu et al., 2011a); PCF } \\
\text { FLM filled with alcohol (Qian et al., 2011); PCF FLM with core offset (Dong, B. et } \\
\text { al., 2011); magneto-optic modulator (Zu et al., 2011b); tapered FLM (Zibaii et al., } \\
\text { 2011) }\end{array}$ \\
\hline
\end{tabular}

Table 1. Hi-Bi FLM configurations chronology.

based on a Hi-Bi fiber Sagnac ring configuration was investigated (see Figure 1 b) (Campbell et al., 1997). In 1999, the same authors reported similar work using a frequency-modulated continuous wave (Campbell et al., 1999).

In 2004, temperature dependence of a polarization maintaining (PM) photonic crystal fiber (PCF) in a Sagnac loop interferometer was analyzed. Comparing with a standard PM fiber, they obtained reduced temperature sensitivity (Kim, D. H. \& Kang, 2004). A temperature insensitive $\mathrm{Hi}-\mathrm{Bi}$ FLM using a photonic crystal fiber was demonstrated. For low-temperatures $\left(25^{\circ} \mathrm{C}\right.$ to $\left.85^{\circ} \mathrm{C}\right)$, a wavelength spacing variation of $0.05 \mathrm{pm} /{ }^{\circ} \mathrm{C}$ was achieved (Zhao et al., 2004).

In 2005, the characteristics of a Hi-Bi FLM composed of a standard $3 \mathrm{~dB}$ fiber coupler with one or more sections of $\mathrm{Hi}-\mathrm{Bi}$ fibers were discussed, as can be seen in Figure $1 \mathrm{c}$ ). Displacement and temperature sensors were theoretically and experimentally analyzed. 
a) $\mid \overline{\mathrm{N}} \overline{\mathrm{d}} \mathrm{3}+\overline{\mathrm{Fib}} \overline{\mathrm{r}} \mathrm{|}$

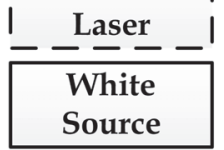

Optical Spectrum Analyzer

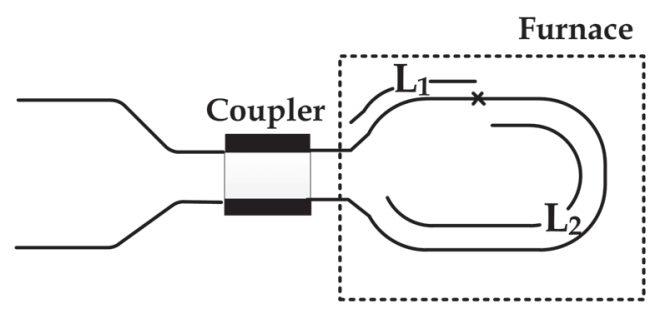

b) $\quad \mathrm{HE}_{11^{\mathrm{y}}}^{\mathrm{y}}$ mode beams

\section{mode coupler}

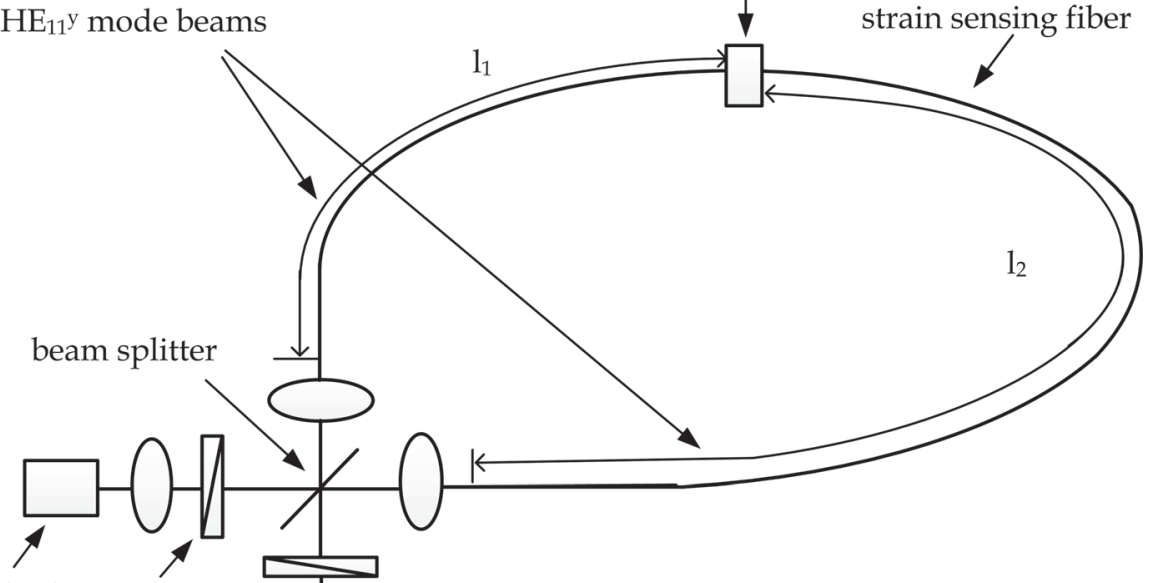

laser diode polariser 1

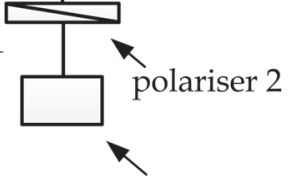

PIN detector

c)

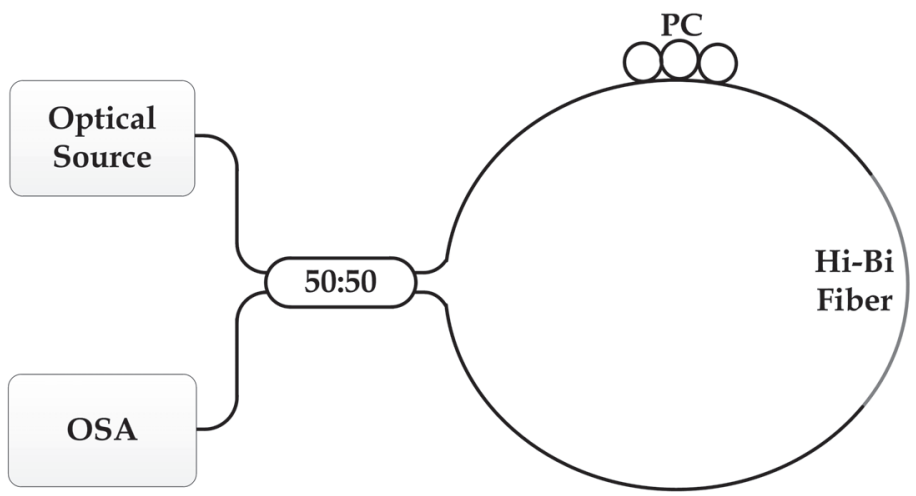

Fig. 1. a) First temperature sensor using a Sagnac interferometer, b) First strain sensor and c) conventional Hi-Bi FLM. 
Using the characteristics of the Hi-Bi FLM, a strain-temperature sensor was proposed and demonstrated as an interrogation system for new applications (Liu et al., 2005). A temperature insensitive fiber Bragg grating (FBG) sensor interrogation system, which used a PCF in a Hi-Bi FLM was proposed and experimentally demonstrated (Yang et al., 2005).

In 2006, a liquid-level Hi-Bi FLM sensor based on a uniform-strength cantilever beam was presented (Dong, B. et al., 2006). The advantages of this sensor included its simple structure, high sensitivity, low-cost and repeatability. A FBG interrogation scheme based on a Hi-Bi FLM for strain-temperature discrimination was reported (Frazao et al., 2006a). The configuration improvement was the use of a Hi-Bi FLM to interrogate an array of FBGs. The same author proposed an alternative solution for simultaneous measurement of strain and temperature, using a long-period fiber grating (LPG) combined with a Hi-Bi FLM (Frazao et al., 2006b).

In 2007, a fiber-optic strain sensor was demonstrated by using a short length of PCF inserted in a Hi-Bi FLM (Dong, X. Y. et. al., 2007). This strain sensor presented temperature insensitivity. The investigation was done using an acrylate coated PCF and other uncoated. Strain and temperature measurements were made to verify their sensibilities (Frazao et al., 2007b). The uncoated PCF revealed insensitivity to temperature. Another work made by the same author (Frazao et al., 2007c) was the birefringence control of a Hi-Bi fiber (bow-tie) under chemical etching. This fiber was inserted in a FLM and the optical response was measured while chemical etching of the bow-tie fiber was taking place. A different study made, was a configuration for simultaneous strain and temperature discrimination using two concatenated Hi-Bi FLMs (Frazao et al., 2007d). By monitoring the wavelength and optical power, it was possible to obtain both measurements simultaneously.

In 2008, an optical current sensor based on Hi-Bi FLM was reported (Marques et al., 2008). An elliptical cladding fiber was coated with a metal and inserted as a sensing element in the FLM. A novel intrinsic fiber optic pressure sensor, based on a PM-PCF section inserted between the output ports of the Hi-Bi FLM was presented (Fu et al., 2008). This sensing head did not require polarimetric detection as the ones reported so far, and through wavelength shifts they obtained a sensitivity of $3.42 \mathrm{~nm} / \mathrm{MPa}$ for a $58.4 \mathrm{~cm}$ long PM-PCF. A setup where the $\mathrm{Hi}-\mathrm{Bi}$ section was combined with a FBG, enabling the simultaneous measurement of strain and temperature was presented (Zhou et al., 2008). The obtained sensing resolution was of $\pm 1{ }^{\circ} \mathrm{C}$ for temperature and $\pm 21 \mu \varepsilon$ for strain. A Hi-Bi PANDA Erbium-doped FLM was presented for the first time. In this case, a temperature coefficient sensitivity of $-2.22 \mathrm{~nm} /{ }^{\circ} \mathrm{C}$ was achieved (Frazao et al., 2008a). Another report by the same author was a Hi-Bi D-type FLM used as refractometer (Frazao et al., 2008b). A chemical etching was applied to the D-type fiber and presented high sensitivity to refractive index. In the same year, a configuration for simultaneous measurement of multiparameters by using a PM side-hole fiber section in the FLM was proposed (Frazao et al., 2008c). Different parameters were analyzed, like torsion, temperature and longitudinal strain.

In the year of 2009, high temperature sensitivity was achieved when a section of birefringent holey fiber filled with metal indium was introduced in a FLM (Kim, B. H. et al., 2009). The analysis was done for wavelength and birefringence responses to temperature, and sensitivities of $-6.3 \mathrm{~nm} / \mathrm{K}$ and $-3.3 \times 10^{-6} \mathrm{~K}^{-1}$ were respectively obtained. On the other hand, 
an elliptical hollow-core photonic bandgap fiber was fabricated and tested in a FLM configuration (Kim, G. et al., 2009), measuring strain and temperature responses. Later on, simultaneous measurement of temperature and strain was performed by using a PM-PCF with Erbium-doped fiber incorporated (Han et al., 2009). Finally, three different multiplexing schemes for PCF FLMs were presented (Fu et al., 2009).

In 2010, a temperature-insensitive displacement sensor, based on Hi-Bi PCFLM was proposed (Zhang et al., 2010). This sensor presented a displacement sensitivity of $0.28286 \mathrm{~nm} / \mathrm{mm}$ and good stability through a temperature range from $40{ }^{\circ} \mathrm{C}$ to $109.5^{\circ} \mathrm{C}$. A low-birefringence PCF FLM as a curvature sensor was reported for the first time (Gong et al., 2010). A sensitivity of $-0.337 \mathrm{~nm}$ for a range between $0-9.92 \mathrm{~m}^{-1}$ was achieved. This sensor was also sensitive to temperature, transverse load and twist, thus being a potential multifunction sensor. A temperature sensor using a section of pressure-induced birefringent SMF FLM was firstly presented (Jin et al., 2010). A sensitivity of $0.65 \mathrm{~nm} /{ }^{\circ} \mathrm{C}$ was reported. A temperature-independent strain sensor based on intensity measurements was developed (Qian et al., 2010). A small core microstructured fiber segment in the FLM for the simultaneous measurement of strain and temperature was used (Andre et al., 2010). Besides $\mathrm{Hi}-\mathrm{Bi}$, this configuration also showed intermodal interference, resulting in a complex channeled spectrum. With a sensing head composed only by a fiber section, resolutions of $\pm 1.5^{\circ} \mathrm{C}$ and $\pm 4.7 \mu \varepsilon$ for temperature and strain were respectively obtained. A torsion sensor with temperature and strain independence, using a suspended twin-core fiber to form the Hi-Bi FLM was investigated (Frazao et al., 2010). The variations in amplitude caused by applying torsion on the sensing head were analyzed by the Fast Fourier Transform technique. Another torsion sensor was done by placing a PCF in a FLM and demonstrated its temperature insensitivity (Kim, H. M. et al., 2010). The variation of reflectivity for long-distance remote FGB cavity sensors using a Hi-Bi FLM was analyzed and demonstrated (Lee et al., 2010).

In 2011, a curvature sensor with a new Hi-Bi PCF design spliced inside the loop mirror was demonstrated (Hwang et al., 2011). The proposed PCF had two large air holes in the outer cladding region that gave rise to core ellipticity during the fabrication process. The curvature sensor is based on the PCF Sagnac interferometer and its sensitivity depended on the bending directions with respect to the large-air-hole alignment. A simultaneous measurement of strain and temperature based on cladding-mode-resonance in PM PCF loop mirror was reported (Dong, B. et al., 2011). By introducing a mode field diameter mismatch at a splicing joint of an inbuilt SMF-PMPCF-SMF structure connected in a Sagnac configuration, an intermodal interference was constructed by the excited cladding modes and the polarization modes of the PMPCF. An optical fiber transverse mechanical load sensor using a short section of solid core PCF which was inserted inside a FLM was reported (Zu et al., 2011a). Two new configurations of Hi-Bi FLMs with an output port probe were proposed (Frazao et al., 2011). Both configurations used two couplers spliced in between, with unbalanced arms and one output port was used as the probe sensor. The difference between them was the location of the Hi-Bi fiber section length: either between the two couplers (first new configuration) or spliced at the output port probe (second new configuration). These configurations were compared with the conventional Hi-Bi FLM when strain was applied and showed similar sensitivities. The theoretical model of these two configurations was studied by (Silva et al., 2011). A compact temperature sensor based on a 
FLM combined with an alcohol-filled Hi-Bi PCF was investigated (Qian et al., 2011). A magneto-optic modulator with a magnetic fluid film inserted into an optical fiber Sagnac interferometer was proposed ( $\mathrm{Zu}$ et al., 2011b) The magnetic fluid exhibited variable birefringence and Faraday effect under external magnetic field that led to a phase difference and polarization state rotation in the Sagnac interferometer. A Hi-Bi FLM with a LPG inscribed in PMF was proposed and experimentally demonstrated for simultaneous measurement of strain and temperature (Kang et al., 2011). This was due to the different responses of the LPG and the Sagnac interferometer observed. A Hi-Bi photonic bandgap Bragg FLM configuration for simultaneous measurement of strain and temperature was reported (Ferreira et al., 2011). The group birefringence and the sharp loss peaks were observable in the spectral response. Since the sensing head presented different sensitivities for strain and temperature measurands, these physical parameters were discriminated by using the matrix method. A single-mode non-adiabatic tapered optical fiber sensor inserted in a FLM enabling to tune its sensitivity towards refractive index was reported (Zibaii et al., 2011).

\section{Birefringence concept}

The Hi-Bi FLM consists in a coupler and a Hi-Bi fiber section as a sensing head. The pattern fringe is obtained through the fiber characteristics. The birefringence is guaranteed in the fabrication process through the geometrical or stress effects. The geometrical effect is easily obtained when the core is non-circular, for example, the elliptical core fiber. The stress effect can be obtained by applying mechanical tension around the core, as occurs in the case of PANDA or bow-tie fibers.

The birefringence effect in optical fibers was studied considering the phase and group modal birefringence. The phase modal birefringence is defined as:

$$
B(\lambda) \equiv n_{x}-n_{y}=\frac{\lambda}{2 \pi}\left(\beta_{x}(\lambda)-\beta_{y}(\lambda)\right),
$$

where $\beta_{i}(i=x, y)$ is the propagation constant associated to each fundamental mode of polarization. This birefringence is associated to the beat length, $L_{B}$, through the relation:

$$
L_{B}=\frac{\lambda}{B(\lambda)}
$$

The group modal birefringence, $G(\lambda)$, is given by:

$$
G(\lambda)=\frac{d \beta_{x}(\lambda)}{d k}-\frac{d \beta_{y}(\lambda)}{d k}=B(\lambda)-\lambda \frac{d B(\lambda)}{d \lambda}
$$

where $k=2 \pi / \lambda$. The differential phase between two polarization modes after propagating through an extension $L$ of fiber is given by:

$$
\phi=\frac{2 \pi L B(\lambda)}{\lambda}
$$


resulting in a channeled type interferometric spectral response, as illustrated in Figure 2.

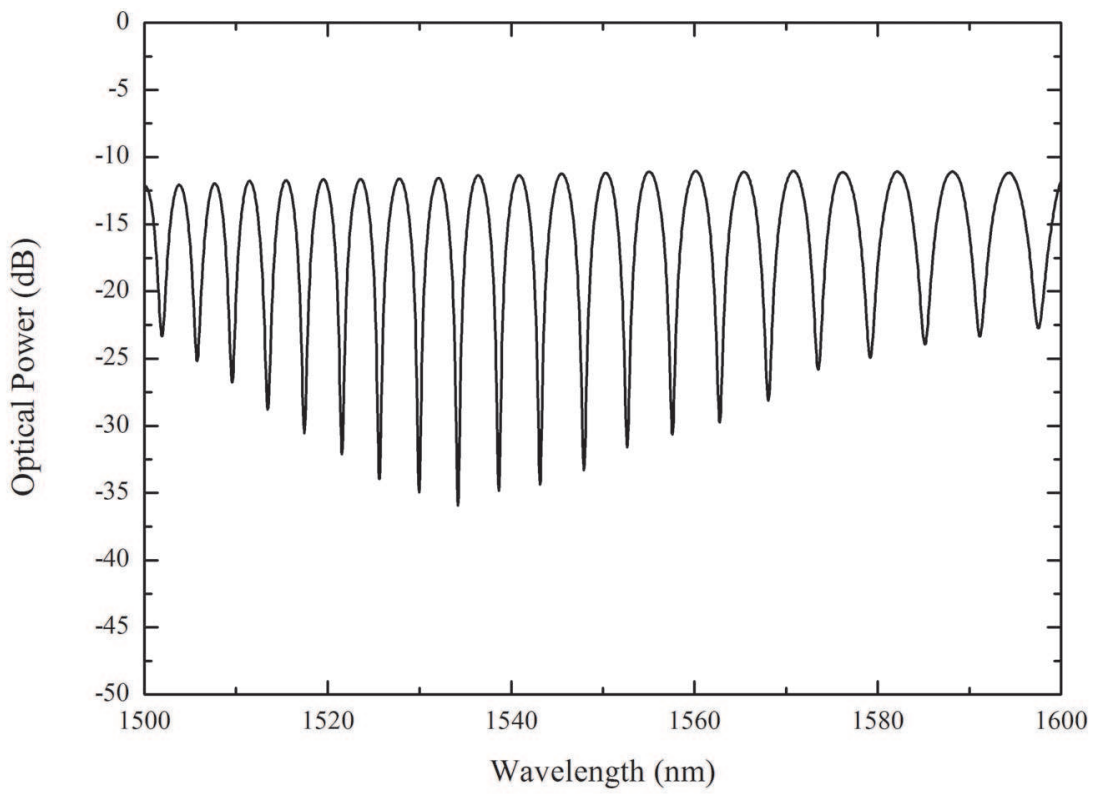

Fig. 2. Typical spectral response of an interferometric structure.

Deriving the phase $\phi$ with respect to $\lambda$, the following equation is obtained:

$$
\frac{d \phi}{d \lambda}=\frac{2 \pi L}{\lambda^{2}}\left(\lambda \frac{d B(\lambda)}{d \lambda}-B(\lambda)\right)=-\frac{2 \pi L}{\lambda^{2}} G(\lambda)
$$

If $\Delta \lambda$ is the channeled spectrum period, corresponding to a phase variation $d \phi=2 \pi$, the expression obtained for the group modal birefringence is:

$$
G(\lambda)=-\frac{\lambda^{2}}{\Delta \lambda L}
$$

\section{New developments}

New developments have been proposed using the FLM in novel designs. Recently, three new Hi-Bi fiber loop mirror with output port probe configurations were demonstrated. These configurations present new solutions as sensing elements. One of them is to use the output port as optical refractometer without the Hi-Bi fiber section or conventional strain/temperature sensors when the probe is a Hi-Bi fiber section.

A torsion sensor with insensitivity to temperature and strain measurement is also demonstrated. In this case the conventional optical coupler is changed by a Hi-Bi coupler where the optical path difference is obtained when the two output arms are unbanlanced. These two new configurations are presented in the following sections. 


\subsection{Hi-Bi FLM with output probe}

Three novel configurations of Hi-Bi FLMs are schematically shown in Figure 3. They consist of a loop of optical fiber formed between the output ports of two directional couplers along with an output port probe.

The first configuration proposed has a polarization controller and a Hi-Bi fiber section located between the optical couplers, (Figure 3 a)). The mode of operation is similar to the conventional FLM. In the first coupler, the light is divided in two waves that travel between the two couplers with asymmetric arms and re-couple in the output port of the second directional coupler. No interference is obtained in the output port of the second coupler because the arms between the two couplers are unbalanced. A silver mirror was fabricated in the end of the fiber tip to re-inject the light into the second coupler. Here the two waves are divided in four waves and re-injected into the first coupler.

Only the two waves that travel in different paths in the two couplers section in the downlead and uplead propagation have a path imbalance associated with the Hi-Bi fiber and, therefore, it is obtained a channeled spectrum with a periodicity similar to what is expectable when considering the standard configuration. The other two waves accumulate a substantial path imbalance and therefore the corresponding channeled spectrum has a very small periodicity, not resolvable by the OSA used. Therefore, the fringe pattern observed in the OSA comes out from the phase difference between the polarization states of the Hi-Bi fiber length. In this case, this configuration was characterized as optical refractometer (Frazao et al., 2011).

The main advantage of this configuration is that other types of interferometers (such as Fabry-Perot) can be inserted in the probe end with a reference provided by the Hi-Bi fiber section.

The second configuration proposed (Figure $3 \mathrm{~b}$ )) is more attractive in general. Here, the $\mathrm{Hi}$-Bi fiber section is spliced to one output port of the second directional coupler. This means that the configuration can be used for remote sensing using only one fiber in the sensing zone. There is a section of an end mirrored Hi-Bi fiber at the second coupler output port, that will increase the returned optical power. It is clear that with this structure it is possible to have the sensing advantages of a FLM without the need of locating geometrically the sensing head inside the loop. A feature that increases the flexibility of the configuration shown in Figure $3 \mathrm{~b}$ ) is the fact that the polarization controller is only needed to adjust the interferometric visibility. This configuration was compared with the conventional Hi-Bi FLM and presents similar sensitivity when the strain is applied (Frazao et al., 2011).

The last configuration (Figure $3 \mathrm{c}$ )) was characterized as an interrogation setup for strain measurement. In this case, two Hi-Bi fiber sections are used as sensor and reference. The setup is formed by two simple couplers with low insertion loss, where the two output ports of the first coupler are spliced to the two input ports of the second one. In one of the splices, a Hi-Bi fiber section (reference) is inserted, while in the other arm a polarization controller is placed, in order to optimize the spectral response of the fringe pattern. The sensor is located at the output port of the second coupler and consists of the same type of Hi-Bi fiber. With the insertion of two Hi-Bi fiber sections, the configuration will have two combined unbalanced Sagnac interferometers. The Hi-Bi fiber used has a length of $1.34 \mathrm{~m}$ and $0.34 \mathrm{~m}$ for the reference and sensor signal, respectively. A signal processing based on the phase-shift quadrature of the two peaks power response of the reference signal was done in real time. 
a)

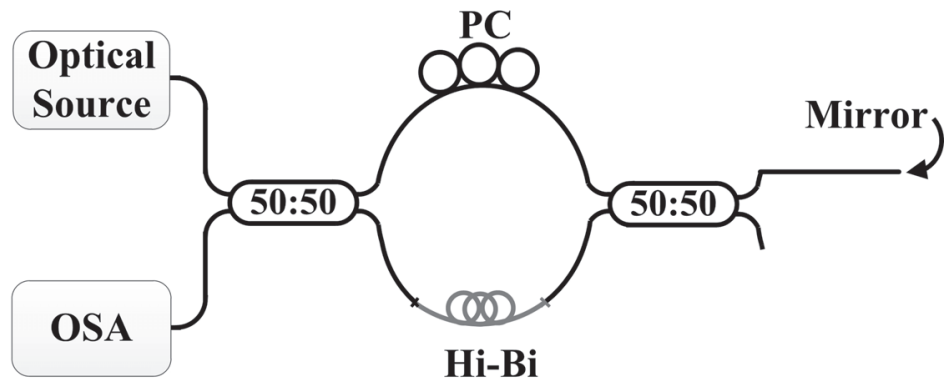

b)
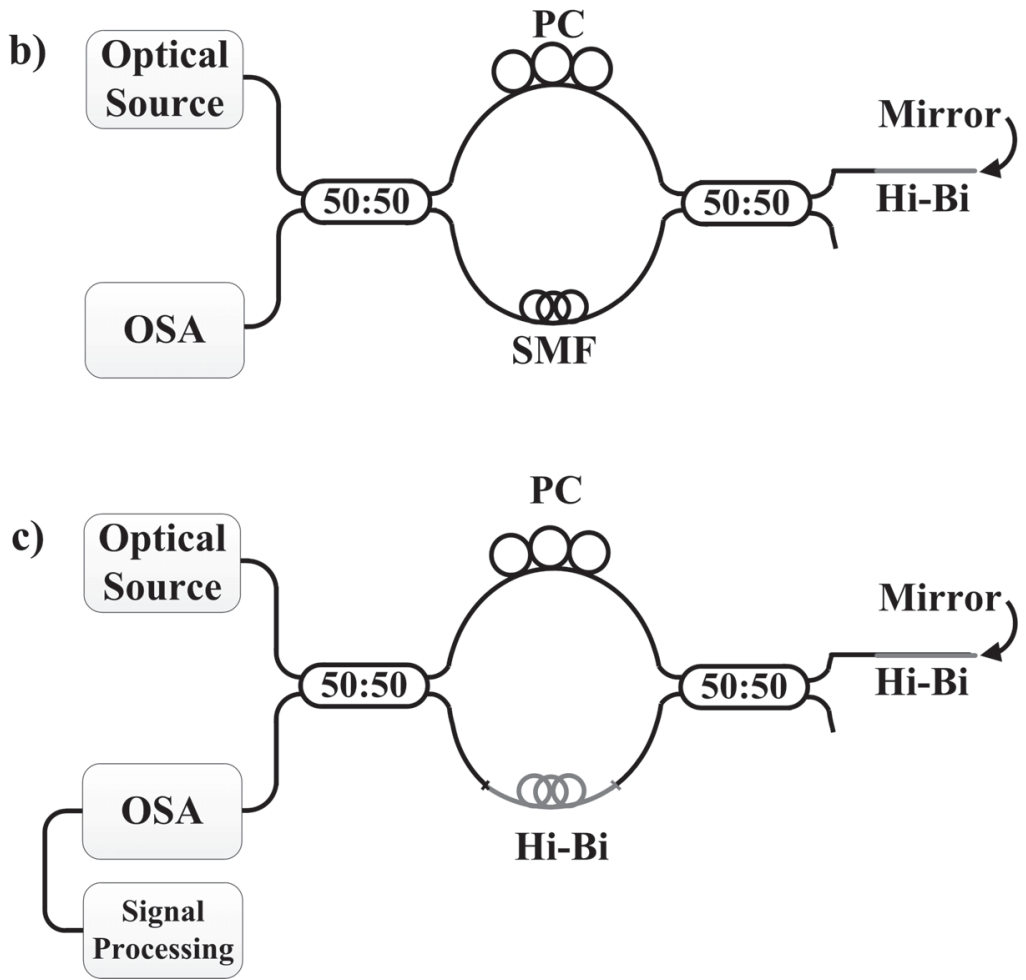

Fig. 3. Schematic setup for the: a) first; b) second; and c) third new Hi-Bi FLM configurations. 
The sensitivity achieved in strain measurements is $16 \mathrm{mrad} / \mu \varepsilon$ (Figure 4). The resolution of the system is $1.9 \mu \varepsilon$, for a strain step variation of $29 \mu \varepsilon$.

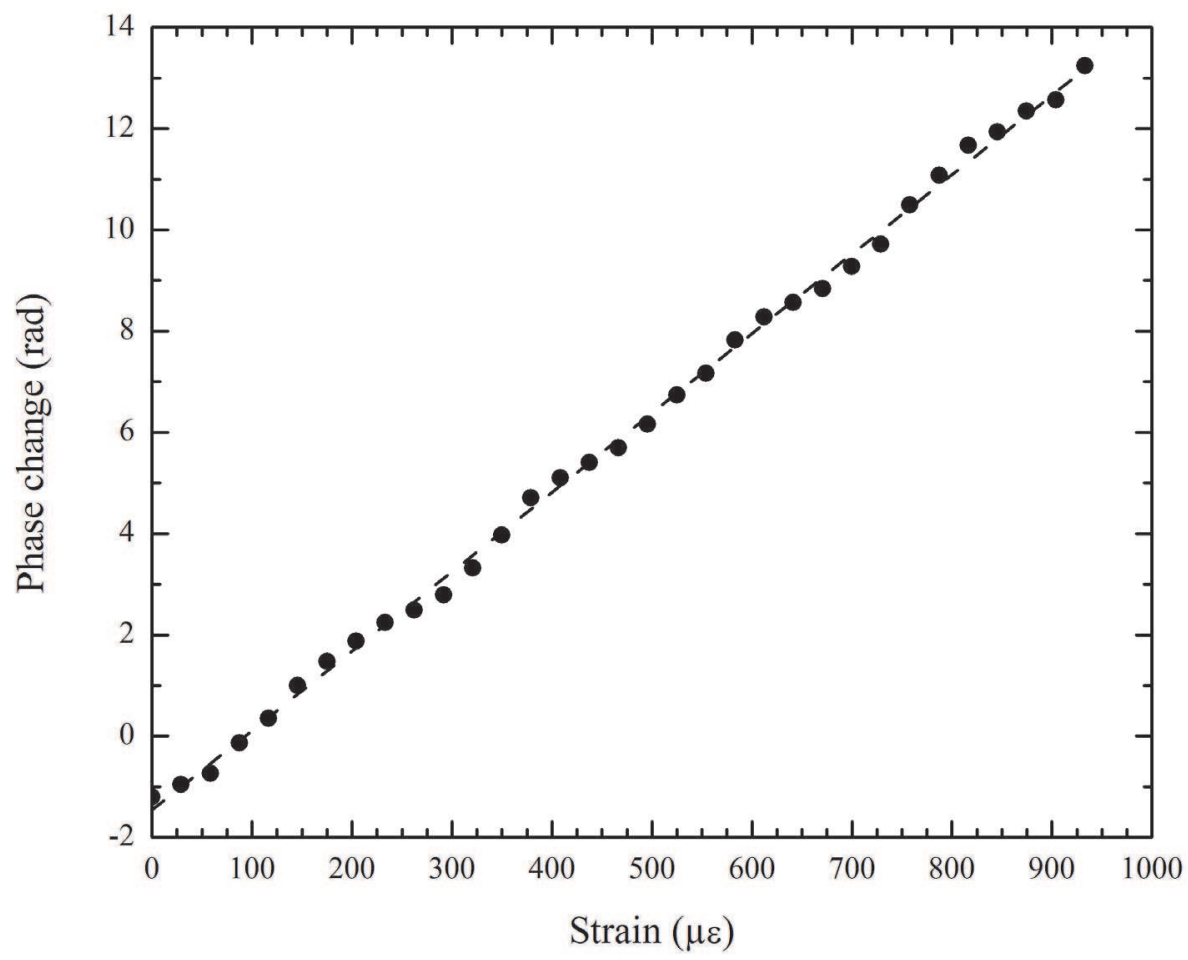

Fig. 4. Phase change versus strain.

\subsection{Torsion sensor using a Sagnac interferometer}

A temperature and strain independent torsion sensor is presented. In this case, the conventional optical coupler is replaced by Hi-Bi fiber coupler and the sensing head consists in a section of standard single mode fiber.

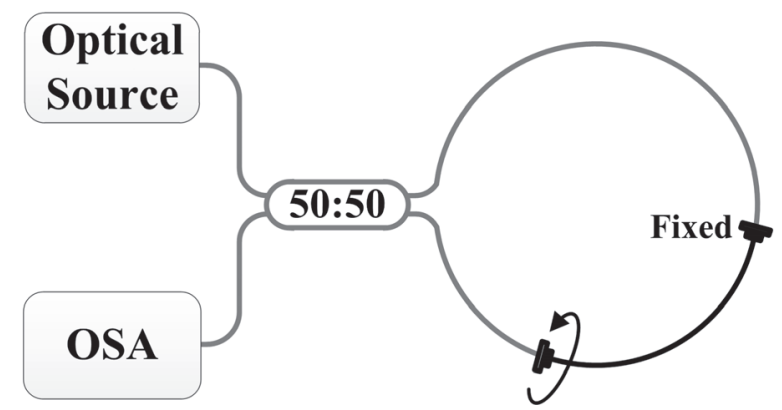

Fig. 5. Experimental setup of the torsion sensor based on Hi-Bi Sagnac loop interferometer. 
Figure 5 presents the experimental setup of a Hi-Bi Sagnac interferometer sensor. Instead of using a regular fiber coupler, a $3 \mathrm{~dB}$ commercial Hi-Bi PANDA fiber coupler is used. This coupler will guarantee that the light will travel through the output arms with a constant polarization. A section of SMF is inserted in order to close the loop.

The interferometer is illuminated with a broadband optical source, and the transmission spectral response of the sensing head is measured with an optical spectrum analyzer (OSA).

The ports length difference of the Hi-Bi coupler will set the fringes pattern, since it introduces a phase accumulation to the travelling wave. The sensing head is located in the SMF region, and torsion measurements can be done by fixing one side of SMF section and twisting the other side, according to Figure 5. As the torsion is applied, an amplitude variation of the spectrum between maximum and minimum values is verified, which induces a change on the visibility of the fringes. Even though the amplitude changes with the torsion angle, total destructive interference is never observed, due to the existence of a beat between the two interferometers. The sensor response is periodically modulated, as the twist is applied. The sensitivity depends on the sensing head length, bigger sensing heads are more sensitive. For a $0.26 \mathrm{~m}$ long sensing head, sensitivities of 0.045 degree $^{-1}$ and -0.051 degree-1 $^{-1}$ were obtained, when left and right twisting angles were respectively applied (Figure 6). The slight difference between the negative sensitivities can be due to the coating effect.

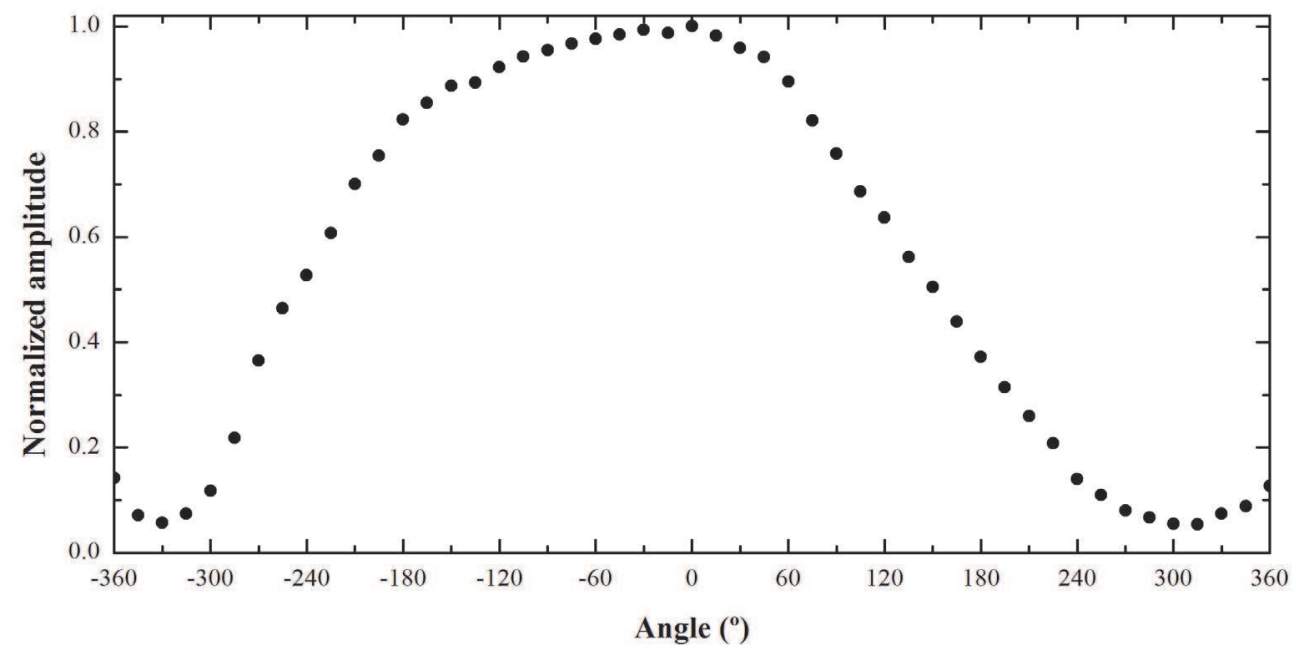

Fig. 6. Torsion measurements of the sensing head.

For temperature measurements, a sensing head with a length of $0.26 \mathrm{~m}$ is placed in a tubular oven, which enables the temperature to be set with an error smaller than $0.1^{\circ} \mathrm{C}$. Regarding strain characterization, the sensing head is attached to a translation stage with a resolution of $1 \mu \mathrm{m}$. The sensitivities obtained are $2 \times 10^{-3} \mathrm{~dB} /{ }^{\circ} \mathrm{C}$ and $7.9 \times 10^{-9} \mathrm{~dB} / \mu \varepsilon$, respectively. Due to the low sensitivities obtained, it can be stated that this sensing head is insensitive to these measurands. These results are expected because temperature and strain do not change the polarization states of the two counter propagating waves in the SMF region. 
The main distinctive feature of this setup, when compared with a conventional Hi-Bi fiber loop mirror, is the polarization controller suppression.

\section{Conclusion}

The first optical fiber highly-birefringent Sagnac interferometer was presented in 1997 (Starodumov et al., 1997). This structure has been consistently used in the ambit of conception of new devices and systems in several areas related to the optical fiber technologies, namely in the optical fiber sensors context. By combining optical devices, it was possible to discriminate physical parameters, such as deformation and temperature. With the emerging of new fibers, like the Photonic Crystal Fibers, it is possible to measure one physical parameter with insensitivity to temperature. At last, with the development of new fiber loop mirror designs, it is possible to interrogate and measure the physical parameters with low cost and easily multiplexing with several sensing heads in series. All works recently published demonstrated the interferometric topology versatility of the Sagnac interferometer in the sensing domain. It must be pointed out that it shall be possible to obtain much better resolutions than the ones indicated if adequate signal processing techniques are applied, that allow reading the interferometer phase.

\section{References}

Andre, R. M., Marques, M. B., Roy, P. \& Frazao, O. (2010). Fiber Loop Mirror Using a Small Core Microstructured Fiber for Strain and Temperature Discrimination. IEEE Photonics Technology Letters, vol. 22, No. 15, (Aug 1, 2010), pp. 1120-1122, ISSN 10411135

Campbell, M., Zheng, G., Holmes-Smith, A. S. \& Wallace, P. A. (1999). A frequencymodulated continuous wave birefringent fibre-optic strain sensor based on a Sagnac ring configuration. Measurement Science \& Technology, vol. 10, No. 3, (Mar, 1999), pp. 218-224, ISSN 0957-0233

Campbell, M., Zheng, G., Wallace, P. A. \& Holmessmith, A. S. (1997). A distributed frequency modulation continuous wave fiber stress sensor based on a birefringent Sagnac ring configuration. Optical Review, vol. 4, No. 1A, (Jan-Feb, 1997), pp. 114116, ISSN 1340-6000

Delarosa, E., Zenteno, L. A., Starodumov, A. N. \& Monzon, D. (1997). All-fiber absolute temperature sensor using an unbalanced high-birefringence Sagnac loop. Optics Letters, vol. 22, No. 7, (Apr 1, 1997), pp. 481-483, ISSN 0146-9592

Dong, B., Hao, J. Z., Liaw, C. Y. \& Xu, Z. W. (2011). Cladding-Mode Resonance in Polarization-Maintaining Photonic-Crystal-Fiber-Based Sagnac Interferometer and Its Application for Fiber Sensor. Journal of Lightwave Technology, vol. 29, No. 12, (Jun 15, 2011), pp. 1759-1763, ISSN 0733-8724

Dong, B., Zhao, Q. D., Feng, L. H., Guo, T., Xue, L. F., Li, S. H. \& Gu, H. (2006). Liquid-level sensor with a high-birefringence-fiber loop mirror. Applied Optics, vol. 45, No. 30, (Oct 20, 2006), pp. 7767-7771, ISSN 0003-6935

Dong, X. Y., Tam, H. Y. \& Shum, P. (2007). Temperature-insensitive strain sensor with polarization-maintaining photonic crystal fiber based Sagnac interferometer. Applied Physics Letters, vol. 90, No. 15, (Apr 9, 2007), pp. -, ISSN 0003-6951 
Fang, X. J. \& Claus, R. O. (1995). Polarization-Independent All-Fiber Wavelength-Division Multiplexer Based on a Sagnac Interferometer. Optics Letters, vol. 20, No. 20, (Oct 15, 1995), pp. 2146-2148, ISSN 0146-9592

Ferreira, M. S., Baptista, J. M., Roy, P., Jamier, R., Fevrier, S. \& Frazao, O. (2011). Highly birefringent photonic bandgap Bragg fiber loop mirror for simultaneous measurement of strain and temperature. Optics Letters, vol. 36, No. 6, (Mar 15, 2011), pp. 993-995, ISSN 0146-9592

Frazao, O., Baptista, J. M. \& Santos, J. L. (2007a). Recent advances in high-birefringence fiber loop mirror sensors. Sensors, vol. 7, No. 11, (Nov, 2007a), pp. 2970-2983, ISSN 14248220

Frazao, O., Baptista, J. M. \& Santos, J. L. (2007b). Temperature-independent strain sensor based on a Hi-Bi photonic crystal fiber loop mirror. IEEE Sensors Journal, vol. 7, No. 9-10, (Sep-Oct, 2007b), pp. 1453-1455, ISSN 1530-437X

Frazao, O., Egypto, D., Bittencourt, L. A., Giraldi, M. T. M. R. \& Marques, M. B. (2008a). Temperature sensor using hi-bi erbium-doped fiber loop mirror. Microwave and Optical Technology Letters, vol. 50, No. 12, (Dec, 2008a), pp. 3152-3154, ISSN 08952477

Frazao, O., Guerreiro, A., Santos, J. L. \& Baptista, J. M. (2007c). Birefringence monitoring of a Hi-Bi fibre under chemical etching through a fibre loop mirror. Measurement Science E Technology, vol. 18, No. 12, (Dec, 2007c), pp. N81-N83, ISSN 0957-0233

Frazao, O., Marques, B. V., Jorge, P., Baptista, J. M. \& Santos, J. L. (2008b). High birefringence D-type fibre loop mirror used as refractometer. Sensors and Actuators B-Chemical, vol. 135, No. 1, (Dec 10, 2008b), pp. 108-111, ISSN 0925-4005

Frazao, O., Marques, L. M. \& Baptista, J. M. (2006a). Fibre Bragg grating interrogation based on high-birefringence fibre loop mirror for strain-temperature discrimination. Microwave and Optical Technology Letters, vol. 48, No. 11, (Nov, 2006a), pp. 23262328, ISSN 0895-2477

Frazao, O., Marques, L. M., Santos, S., Baptista, J. M. \& Santos, J. L. (2006b). Simultaneous measurement for strain and temperature based on a long-period grating combined with a high-birefringence fiber loop mirror. IEEE Photonics Technology Letters, vol. 18, No. 21-24, (Nov-Dec, 2006b), pp. 2407-2409, ISSN 1041-1135

Frazao, O., Santos, J. L. \& Baptista, J. M. (2007d). Strain and temperature discrimination using IF concatenated high-birefringence fiber loop mirrors. IEEE Photonics Technology Letters, vol. 19, No. 13-16, (Jul-Aug, 2007d), pp. 1260-1262, ISSN 10411135

Frazao, O., Silva, R. M., Kobelke, J. \& Schuster, K. (2010). Temperature- and strainindependent torsion sensor using a fiber loop mirror based on suspended twin-core fiber. Optics Letters, vol. 35, No. 16, (Aug 15, 2010), pp. 2777-2779, ISSN 0146-9592

Frazao, O., Silva, R. M. \& Santos, J. L. (2011). High-Birefringent Fiber Loop Mirror Sensors With an Output Port Probe. IEEE Photonics Technology Letters, vol. 23, No. 2, (Jan 15, 2011), pp. 103-105, ISSN 1041-1135

Frazao, O., Silva, S. O., Baptista, J. M., Santos, J. L., Statkiewicz-Barabach, G., Urbanczyk, W. \& Wojcik, J. (2008c). Simultaneous measurement of multiparameters using a Sagnac interferometer with polarization maintaining side-hole fiber. Applied Optics, vol. 47, No. 27, (Sep 20, 2008c), pp. 4841-4848, ISSN 0003-6935 
Fu, H. Y., Tam, H. Y., Shao, L. Y., Dong, X. Y., Wai, P. K. A., Lu, C. \& Khijwania, S. K. (2008). Pressure sensor realized with polarization-maintaining photonic crystal fiber-based Sagnac interferometer. Applied Optics, vol. 47, No. 15, (May 20, 2008), pp. 2835-2839, ISSN 0003-6935

Fu, H. Y., Wong, A. C. L., Childs, P. A., Tam, H. Y., Liao, Y. B., Lu, C. \& Wai, P. K. A. (2009). Multiplexing of polarization-maintaining photonic crystal fiber based Sagnac interferometric sensors. Optics Express, vol. 17, No. 21, (Oct 21, 2009), pp. 1850118512, ISSN 1094-4087

Gong, H. P., Chan, C. C., Zu, P., Chen, L. H. \& Dong, X. Y. (2010). Curvature measurement by using low-birefringence photonic crystal fiber based Sagnac loop. Optics Communications, vol. 283, No. 16, (Aug 15, 2010), pp. 3142-3144, ISSN 0030-4018

Han, Y. G., Chung, Y. \& Lee, S. B. (2009). Discrimination of strain and temperature based on a polarization-maintaining photonic crystal fiber incorporating an erbium-doped fiber. Optics Communications, vol. 282, No. 11, (Jun 1, 2009), pp. 2161-2164, ISSN 0030-4018

Hwang, K. J., Kim, G. H., Lim, S. D., Lee, K., Park, J. W. \& Lee, S. B. (2011). A Novel Birefringent Photonic Crystal Fiber and Its Application to Curvature Measurement. Japanese Journal of Applied Physics, vol. 50, No. 3, (Mar, 2011), pp. -, ISSN 0021-4922

Jin, Y. X., Chan, C. C., Zhang, Y. F., Dong, X. Y. \& Zu, P. (2010). Temperature sensor based on a pressure-induced birefringent single-mode fiber loop mirror. Measurement Science E Technology, vol. 21, No. 6, (Jun, 2010), pp. -, ISSN 0957-0233

Kang, J. A., Dong, X. Y., Zhao, C. L., Qian, W. W. \& Li, M. C. (2011). Simultaneous measurement of strain and temperature with a long-period fiber grating inscribed Sagnac interferometer. Optics Communications, vol. 284, No. 8, (Apr 15, 2011), pp. 2145-2148, ISSN 0030-4018

Kim, B. H., Lee, S. H., Lin, A. X., Lee, C. L., Lee, J. \& Han, W. T. (2009). Large temperature sensitivity of Sagnac loop interferometer based on the birefringent holey fiber filled with metal indium. Optics Express, vol. 17, No. 3, (Feb 2, 2009), pp. 1789-1794, ISSN 1094-4087

Kim, D. H. \& Kang, J. U. (2004). Sagnac loop interferometer based on polarization maintaining photonic crystal fiber with reduced temperature sensitivity. Optics Express, vol. 12, No. 19, (Sep 20, 2004), pp. 4490-4495, ISSN 1094-4087

Kim, G., Cho, T. Y., Hwang, K., Lee, K., Lee, K. S., Han, Y. G. \& Lee, S. B. (2009). Strain and temperature sensitivities of an elliptical hollow-core photonic bandgap fiber based on Sagnac interferometer. Optics Express, vol. 17, No. 4, (Feb 16, 2009), pp. 24812486, ISSN 1094-4087

Kim, H. M., Kim, T. H., Kim, B. \& Chung, Y. (2010). Temperature-Insensitive Torsion Sensor With Enhanced Sensitivity by Use of a Highly Birefringent Photonic Crystal Fiber. IEEE Photonics Technology Letters, vol. 22, No. 20, (Oct 15, 2010), pp. 1539-1541, ISSN 1041-1135

Lee, T. H., Lee, H. D., Kim, C. S. \& Jeong, M. Y. (2010). Characterization of variable reflectivity of a polarization-maintaining fiber Sagnac mirror for long-distance remote fiber Bragg gratings cavity sensors. Measurement Science \& Technology, vol. 21, No. 11, (Nov, 2010), pp. -, ISSN 0957-0233 
Liu, Y., Liu, B., Feng, X. H., Zhang, W. G., Zhou, G., Yuan, S. Z., Kai, G. Y. \& Dong, X. Y. (2005). High-birefringence fiber loop mirrors and their applications as sensors. Applied Optics, vol. 44, No. 12, (Apr 20, 2005), pp. 2382-2390, ISSN 0003-6935

Marques, B. V., Frazao, O., Mendonca, S., Perez, J., Marques, M. B., Santos, S. F. \& Baptista, J. M. (2008). Optical current sensor based on metal coated Hi-Bi fiber loop mirror. Microwave and Optical Technology Letters, vol. 50, No. 3, (Mar, 2008), pp. 780-782, ISSN 0895-2477

Mortimore, D. B. (1988). Fiber Loop Reflectors. Journal of Lightwave Technology, vol. 6, No. 7, (Jul, 1988), pp. 1217-1224, ISSN 0733-8724

Qian, W. W., Zhao, C. L., Dong, X. Y. \& Jin, W. (2010). Intensity measurement based temperature-independent strain sensor using a highly birefringent photonic crystal fiber loop mirror. Optics Communications, vol. 283, No. 24, (Dec 15, 2010), pp. 52505254, ISSN 0030-4018

Qian, W. W., Zhao, C. L., He, S. L., Dong, X. Y., Zhang, S. Q., Zhang, Z. X., Jin, S. Z., Guo, J. T. \& Wei, H. F. (2011). High-sensitivity temperature sensor based on an alcoholfilled photonic crystal fiber loop mirror. Optics Letters, vol. 36, No. 9, (May 1, 2011), pp. 1548-1550, ISSN 0146-9592

Silva, R. M., Layeghi, A., Zibaii, M. I., Santos, J. L. \& Frazão, O. (2011). Theoretical and Experimental Results of High Birefringent Fiber Loop Mirror with an Output Port Probe. Journal of Lightwave Technology, vol. -, No. -, 2011), pp. -, -(Submitted)

Starodumov, A. N., Zenteno, L. A., Monzon, D. \& Delarosa, E. (1997). Fiber Sagnac interferometer temperature sensor. Applied Physics Letters, vol. 70, No. 1, (Jan 6, 1997), pp. 19-21, ISSN 0003-6951

Urquhart, P. (1989). Fiber Lasers with Loop Reflectors. Applied Optics, vol. 28, No. 17, (Sep 1, 1989), pp. 3759-3767, ISSN 0740-3224

Yang, X. F., Zhao, C. L., Peng, Q. Z., Zhou, X. Q. \& Lu, C. (2005). FBG sensor interrogation with high temperature insensitivity by using a HiBi-PCF Sagnac loop filter. Optics Communications, vol. 250, No. 1-3, (Jun 1, 2005), pp. 63-68, ISSN 0030-4018

Zhang, H., Liu, B., Wang, Z., Luo, J. H., Wang, S. X., Jia, C. H. \& Ma, X. R. (2010). Temperature-insensitive displacement sensor based on high-birefringence photonic crystal fiber loop mirror. Optica Applicata, vol. 40, No. 1, 2010), pp. 209-217, ISSN 0078-5466

Zhao, C. L., Yang, X. F., Lu, C., Jin, W. \& Demokan, M. S. (2004). Temperature-insensitive interferometer using a highly birefringent photonic crystal fiber loop mirror. IEEE Photonics Technology Letters, vol. 16, No. 11, (Nov, 2004), pp. 2535-2537, ISSN 10411135

Zhou, D. P., Wei, L., Liu, W. K. \& Lit, J. W. Y. (2008). Simultaneous measurement of strain and temperature based on a fiber Bragg grating combined with a highbirefringence fiber loop mirror. Optics Communications, vol. 281, No. 18, (Sep 15, 2008), pp. 4640-4643, ISSN 0030-4018

Zibaii, M. I., Latifi, H., Frazão, O. \& Jorge, P. a. S. (2011). Controlling the Sensitivity of Refractive Index Measurement using a Tapered Fiber Loop Mirror. IEEE Photonics Technology Letters, (2011), (Accepted)

Zu, P., Chan, C. C., Jin, Y. X., Zhang, Y. F. \& Dong, X. Y. (2011a). Fabrication of a temperature-insensitive transverse mechanical load sensor by using a photonic 
crystal fiber-based Sagnac loop. Measurement Science \& Technology, vol. 22, No. 2, (Feb, 2011a), ISSN 0957-0233

Zu, P., Chan, C. C., Siang, L. W., Jin, Y. X., Zhang, Y. F., Fen, L. H., Chen, L. H. \& Dong, X. Y. (2011b). Magneto-optic fiber Sagnac modulator based on magnetic fluids. Optics Letters, vol. 36, No. 8, (Apr 15, 2011b), pp. 1425-1427, ISSN 0146-9592 


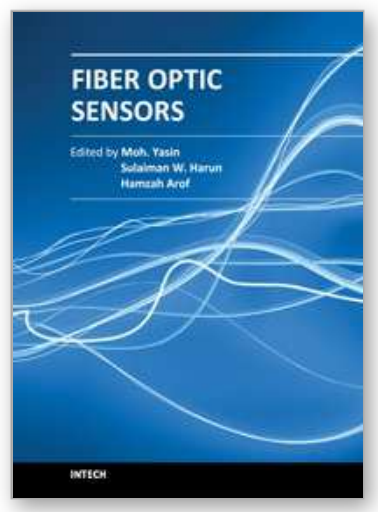

\author{
Fiber Optic Sensors \\ Edited by Dr Moh. Yasin
}

ISBN 978-953-307-922-6

Hard cover, 518 pages

Publisher InTech

Published online 22, February, 2012

Published in print edition February, 2012

This book presents a comprehensive account of recent advances and researches in fiber optic sensor technology. It consists of 21 chapters encompassing the recent progress in the subject, basic principles of various sensor types, their applications in structural health monitoring and the measurement of various physical, chemical and biological parameters. It also highlights the development of fiber optic sensors, their applications by providing various new methods for sensing and systems, and describing recent developments in fiber Bragg grating, tapered optical fiber, polymer optical fiber, long period fiber grating, reflectometry and interefometry based sensors. Edited by three scientists with a wide knowledge of the field and the community, the book brings together leading academics and practitioners in a comprehensive and incisive treatment of the subject. This is an essential reference for researchers working and teaching in optical fiber sensor technology, and for industrial users who need to be aware of current developments and new areas in optical fiber sensor devices.

\title{
How to reference
}

In order to correctly reference this scholarly work, feel free to copy and paste the following:

Marta S. Ferreira, Ricardo M. Silva and Orlando Frazão (2012). High-Birefringent Fiber Loop Mirror Sensors: New Developments, Fiber Optic Sensors, Dr Moh. Yasin (Ed.), ISBN: 978-953-307-922-6, InTech, Available from: http://www.intechopen.com/books/fiber-optic-sensors/high-birefringent-fiber-loop-mirror-sensors-newdevelopments

\section{INTECH}

open science | open minds

\section{InTech Europe}

University Campus STeP Ri

Slavka Krautzeka 83/A

51000 Rijeka, Croatia

Phone: +385 (51) 770447

Fax: +385 (51) 686166

www.intechopen.com

\section{InTech China}

Unit 405, Office Block, Hotel Equatorial Shanghai

No.65, Yan An Road (West), Shanghai, 200040, China

中国上海市延安西路65号上海国际贵都大饭店办公楼 405 单元

Phone: +86-21-62489820

Fax: $+86-21-62489821$ 
(C) 2012 The Author(s). Licensee IntechOpen. This is an open access article distributed under the terms of the Creative Commons Attribution 3.0 License, which permits unrestricted use, distribution, and reproduction in any medium, provided the original work is properly cited. 